\title{
A cytotoxic phenotype does not predict clinical outcome in anaplastic large cell lymphomas
} D F Dukers, R L ten Berge, J J Oudejans, K Pulford, D Hayes, J F M M Miseré,
G J Ossenkoppele, L H Jaspars, R Willemze, C J L M Meijer
Department of Pathology, Academic Hospital, Vrije Universiteit, De Boelelaan 1117, 1081 HV Amsterdam, The Netherlands D F Dukers $\mathrm{R} L$ ten Berge J J Oudejans D Hayes

L H Jaspars

C J L M Meijer

Department of Haematology, Academic Hospital, Vrije Universiteit, Amsterdam G J Ossenkoppele

Department of Dermatology, Academic Hospital, Vrije Universiteit, Amsterdam $\mathrm{R}$ Willemze

Department of Cellular Science, John Radcliffe Hospital, Oxford, UK K Pulford

Department of Pathology, St Elizabeth Hospital, Tilburg, The Netherlands

J F M M Miseré

Correspondence to: Dr Dukers. email: d.dukers@azvu.nl

Accepted for publication 11 August 1998

\begin{abstract}
Aim-To investigate whether anaplastic large cell lymphomas (ALCL) expressing cytotoxic proteins have a relatively worse clinical outcome compared with ALCL lacking a cytotoxic phenotype.

Methods-59 primary cases of ALCL originating from different sites were investigated by immunohistochemistry for the presence of the cytotoxic proteins $T$ cell intracytoplasmic antigen (TIA-1) and granzyme B in the neoplastic cells. Since site of origin and expression of anaplastic lymphoma kinase (ALK) strongly influence prognosis, the presence of a cytotoxic phenotype was also investigated in relation to the primary site of origin (lymph node, gut, or skin) and ALK expression. The prognostic value was investigated by analysis of overall and relapse-free survival time, including Cox regression analysis.

Results-39 of 59 ALCL (66\%) appeared to have a cytotoxic phenotype as shown by expression of TIA-1 or granzyme $B$ or both in the neoplastic cells. The presence of a cytotoxic phenotype did not have any influence on prognosis. Even when the survival data were corrected for site of origin and stage at presentation or were analysed separately for ALK positive and negative cases, no prognostic influence of a cytotoxic phenotype was observed. Conclusions-In primary biopsies of patients with ALCL, the presence of a cytotoxic phenotype is not related to clinical outcome of the disease.

(f Clin Pathol 1999;52:129-136)
\end{abstract}

Keywords: granzyme B; anaplastic large cell lymphoma; prognosis

Anaplastic large cell lymphomas (ALCL) are considered to be a subgroup of non-Hodgkin's lymphomas (NHL), characterised by the presence of cohesive sheets of large CD30 positive anaplastic cells with prominent nucleoli. ${ }^{1}$ At present only $\mathrm{T}$ cell or null cell proliferations are identified as ALCL in the International Lymphoma Study Group classification proposal. ${ }^{2}$ A consistent finding in a significant proportion of ALCL cases is the $\mathrm{t}(2 ; 5)$ translocation fusing the nucleophosmin gene (NPM) with a tyrosine kinase gene named anaplastic lymphoma kinase (ALK), resulting in NPM/ ALK expression. Although the function of this protein remains unclear, ${ }^{3-6}$ the presence of NPM/ALK fusion protein in neoplastic cells of
ALCL cases has been found to be correlated with a better prognosis. ${ }^{36-8}$

Recent studies indicate that ALCL have phenotypic features of activated cytotoxic $\mathrm{T}$ cells. ${ }^{9-12}$ Using antibodies directed against granzyme $\mathrm{B}$, perforin, and $\mathrm{T}$ cell restricted intracytoplasmic antigen (TIA-1), it is possible to detect a population of cells with potential cytotoxic activity. ${ }^{13-15}$ It has been shown that granzyme B and perforin expression is restricted to activated lymphocytes and natural killer cells, ${ }^{16}{ }^{17}$ whereas TIA-1 is found in both resting and activated cytotoxic $\mathrm{T}$ cells and natural killer cells. In comparison with granzyme B, TIA-1 is more abundantly expressed, in up to $60 \%$ of CD8 positive lymphocytes and in a small minority $(6 \%)$ of CD4 positive T lymphocytes. ${ }^{18}$

It could be hypothesised that lymphomas originating from cytotoxic $\mathrm{T}$ cells (or natural killer cells) may be particularly resistant to apoptosis since cytotoxic $\mathrm{T}$ cells themselves are resistant to perforin/granzyme B mediated lysis. ${ }^{19}$ Several mechanisms are likely to be involved in producing resistance against apoptosis of cytotoxic $T$ cells. There is evidence that an as yet unidentified membrane protein on the surface of cytotoxic $\mathrm{T}$ cells and natural killer cells protects these cells against perforin mediated lysis. ${ }^{19}$ Furthermore, in vitro experiments have shown that (tumour) cells can escape granzyme B mediated apoptosis by expressing certain intracellular serine protease inhibitors (serpins). A recently cloned serpin called PI-9 was shown to be a potent inhibitor of granzyme B mediated apoptosis. ${ }^{20}$ These observations indicate that evasion of granzyme $\mathrm{B}$ /perforin mediated apoptosis might be important in tumour cell resistance against cytotoxic $\mathrm{T}$ cell mediated cytotoxicity. ${ }^{11}{ }^{21}$

Although tumour cells showing resistance to apoptosis induced by cytotoxic $\mathrm{T}$ cells are not inherently also resistant to apoptosis induced by either radiotherapy or chemotherapy, several lines of research indicate that the different apoptosis inducing signals share one or more common final lethal pathways. ${ }^{22-24}$ Thus resistance to cytotoxic $\mathrm{T}$ cell induced apoptosis may also lead to resistance to chemotherapy induced apoptosis, resulting in a poor clinical outcome in ALCL patients in whom the tumour cells show a cytotoxic phenotype.

Since the site of origin and ALK expression strongly influence prognosis, ${ }^{32526}$ we investigated 59 cases of ALCL (44 nodal, three gastrointestinal, and 12 cutaneous) and determined whether a cytotoxic phenotype, alone or in relation to site or ALK expression, 
Table 1 Patient and tumour characteristics at the time of first presentation in all cases used for survival analysis $(n=59)$

\begin{tabular}{|c|c|c|c|c|c|c|}
\hline \multirow[b]{2}{*}{ Characteristic } & \multicolumn{2}{|l|}{ Nodal ALCL } & \multicolumn{2}{|c|}{ Gut associated $A L C L$} & \multicolumn{2}{|l|}{ Cutaneous ALCL } \\
\hline & $\begin{array}{l}\text { GrB/TIA-1 pos } \\
(n=29)\end{array}$ & $\begin{array}{l}\text { GrB/TIA-1 neg } \\
(n=15)\end{array}$ & $\begin{array}{l}\text { GrB/TIA-1 pos } \\
(n=2)\end{array}$ & $\begin{array}{l}\text { GrB/TIA-1 neg } \\
(n=1)\end{array}$ & $\begin{array}{l}\text { GrB/TIA-1 pos } \\
(n=8)\end{array}$ & $\begin{array}{l}\text { GrB/TIA-1 neg } \\
(n=4)\end{array}$ \\
\hline Median age (y) & 39 & 44 & 45 & 74 & 65 & 50 \\
\hline $\operatorname{Sex}(M / F)$ & $19 / 10$ & $10 / 5$ & $1 / 1$ & $0 / 1$ & $5 / 3$ & $4 / 0$ \\
\hline \multicolumn{7}{|l|}{ Disease stage } \\
\hline I & 5 & 4 & 0 & 0 & 8 & 4 \\
\hline II & 9 & 4 & 0 & 1 & 0 & 0 \\
\hline III & 7 & 3 & 2 & 0 & 0 & 0 \\
\hline IV & 8 & 4 & 0 & 0 & 0 & 0 \\
\hline B symptoms & 14 & 10 & 0 & 1 & 0 & 0 \\
\hline $\mathrm{CR}$ & 24 & 11 & 1 & 1 & 8 & 4 \\
\hline Relapse & 11 & 7 & 2 & 0 & 1 & 2 \\
\hline \multicolumn{7}{|l|}{ Cause of death } \\
\hline ALCL & 9 & 6 & 2 & 0 & 0 & 0 \\
\hline Other & 1 & 0 & 0 & 0 & 2 & 0 \\
\hline
\end{tabular}

ALCL, anaplastic large cell lymphoma; CR, complete remission; GrB, granzyme B; TIA-1, T cell intracytoplasmic antigen.

influences the clinical behaviour of these lymphomas in terms of overall survival and relapse-free survival time.

\section{Methods}

PATIENT SELECTION

Paraffin wax embedded tissue specimens of 59 primary anaplastic large cell lymphomas were selected from the archives of the Comprehen- sive Cancer Centre, Amsterdam $(n=56)$ and the St Elizabeth Hospital, Tilburg $(n=3)$. ALCL from different sites of origin - that is, lymph nodes $(n=44)$, gastrointestinal tract $(n=3)$, and skin $(n=12)$-were included.

The diagnosis of ALCL was made according to the criteria of the updated Kiel classification, which is also incorporated in the REAL classification. $^{27}$

Table 2 Patient and tumour characteristics in primary nodal anaplastic large cell lymphomas (ALCL)

\begin{tabular}{|c|c|c|c|c|c|c|c|c|c|c|c|c|}
\hline Case & $G r B^{\star}$ & $T I A-1^{\star}$ & $A L K$ & $C D 3$ & $C D 4$ & $C D 8$ & Stage & $R x$ & $C R$ & Rel & Survt & Status \\
\hline \multicolumn{13}{|c|}{ Nodal $A L C L$ with a cytotoxic phenotype } \\
\hline 1 & 86 & 18 & + & + & - & - & II & PC & + & - & 15 & AAW \\
\hline 2 & 60 & 86 & + & + & - & - & II & $\mathrm{PC}+\mathrm{R}$ & + & - & 46 & AAW \\
\hline 3 & 47 & 92 & + & - & nd & nd & III & PC & + & - & 71 & AAW \\
\hline 4 & 30 & 30 & + & + & + & - & II & $\mathrm{PC}+\mathrm{R}$ & + & - & 51 & AAW \\
\hline 5 & 30 & 30 & + & - & $+/-$ & _ & IV & PC & + & _ & 36 & AAW \\
\hline 6 & 30 & 30 & + & - & + & - & I & $\mathrm{R}$ & + & + & 34 & AWD \\
\hline 7 & 30 & 30 & + & - & + & - & III & PC & + & - & 27 & AAW \\
\hline 8 & 30 & 30 & + & - & - & - & I & PC & + & - & 21 & AAW \\
\hline 9 & 10 & 30 & + & - & - & - & I & $\mathrm{PC}+\mathrm{R}$ & + & - & 9 & AAW \\
\hline 10 & 7 & 27 & + & + & + & - & II & $\mathrm{PC}+\mathrm{R}$ & + & + & 126 & AWD \\
\hline 11 & 1 & 57 & + & + & - & - & II & PC & + & - & 106 & AAW \\
\hline 12 & 0 & 72 & + & - & nd & - & II & PC & + & - & 33 & AAW \\
\hline 13 & 92 & 90 & - & + & - & + & III & PC & + & + & 12 & DOD \\
\hline 14 & 69 & 38 & - & + & - & - & III & PC & + & - & 64 & AAW \\
\hline 15 & 31 & 32 & - & - & nd & - & IV & PC & + & - & 207 & AAW \\
\hline 16 & 30 & 20 & - & + & - & - & IV & PC & + & - & 32 & AAW \\
\hline 17 & 21 & 44 & - & + & + & - & IV & PC & - & + & 1 & DOD \\
\hline 18 & 20 & 63 & - & - & + & - & II & $\mathrm{PC}+\mathrm{R}$ & + & + & 26 & DOD \\
\hline 19 & 20 & 17 & - & - & nd & - & III & $\mathrm{PC}+\mathrm{R}$ & + & + & 8 & DOD \\
\hline 20 & 10 & 30 & - & - & - & - & IV & PC & - & + & 4 & DOD \\
\hline 21 & 10 & 30 & - & - & + & - & III & PC & + & + & 20 & DOD \\
\hline 22 & 10 & 10 & - & - & - & - & I & PC & + & - & 54 & AAW \\
\hline 23 & 10 & 30 & - & + & + & - & IV & PC & - & + & 1 & DOD \\
\hline 24 & 10 & 25 & - & - & + & - & IV & PC & + & - & 7 & DOC \\
\hline 25 & 10 & 10 & - & + & $+/-$ & - & IV & PC & + & - & 29 & AAW \\
\hline 26 & 10 & 10 & - & - & + & - & II & PC & - & + & 2 & DOD \\
\hline 27 & 1 & 19 & - & - & - & - & I & PC & + & - & 66 & AAW \\
\hline 28 & 0 & 10 & - & - & + & - & III & PC & - & + & 12 & DOD \\
\hline 29 & 5 & 74 & nd & - & - & - & II & PC & + & - & 32 & AAW \\
\hline \multicolumn{13}{|c|}{ Nodal ALCL without a cytotoxic phenotype } \\
\hline 30 & 0 & 0 & + & - & + & - & I & $\mathrm{PC}+\mathrm{R}$ & + & - & 75 & AAW \\
\hline 31 & 0 & 0 & - & - & + & - & I & $\mathrm{PC}+\mathrm{R}$ & + & - & 100 & AAW \\
\hline 32 & 0 & 0 & - & + & - & - & I & $\mathrm{R}$ & + & + & 13 & DOD \\
\hline 33 & 0 & 0 & - & + & nd & nd & III & PC & + & + & 74 & AAW \\
\hline 34 & 0 & 0 & - & + & + & - & II & $\mathrm{PC}+\mathrm{R}$ & + & - & 49 & AAW \\
\hline 35 & 0 & 0 & - & + & - & - & IV & PC & + & - & 44 & AAW \\
\hline 36 & 0 & 0 & - & + & + & - & I & $\mathrm{R}$ & + & + & 25 & DOD \\
\hline 37 & 0 & 0 & - & - & + & - & III & PC & + & - & 22 & AAW \\
\hline 38 & 0 & 0 & - & - & - & - & III & PC & - & + & 2 & DOD \\
\hline 39 & 0 & 0 & - & - & - & - & IV & none & - & + & 0 & DOD \\
\hline 40 & 0 & 0 & - & - & - & - & IV & none & - & + & 1 & DOD \\
\hline 41 & 0 & 0 & - & - & + & - & II & PC & + & - & 5 & AAW \\
\hline 42 & 0 & 0 & - & - & + & - & II & PC & + & - & 12 & AAW \\
\hline 43 & 0 & 0 & - & + & + & nd & IV & PC & - & + & 3 & DOD \\
\hline 44 & 0 & 0 & nd & nd & nd & nd & II & PC & + & - & 10 & AAW \\
\hline
\end{tabular}

AAW, alive and well; ALK, anaplastic lymphoma kinase; AWD, alive with disease; CR, complete remission; DOC, died of other cause; DOD, died of disease; GrB, granzyme B; nd, not determined; PC, polychemotherapy; Rel, relapse; Rx, treatment; Surv, survival; TIA-1, $\mathrm{T}$ cell intracytoplasmic antigen.

^Percentage of positive neoplastic cells determined using the Q-Prodit system.

†Survival in months. 

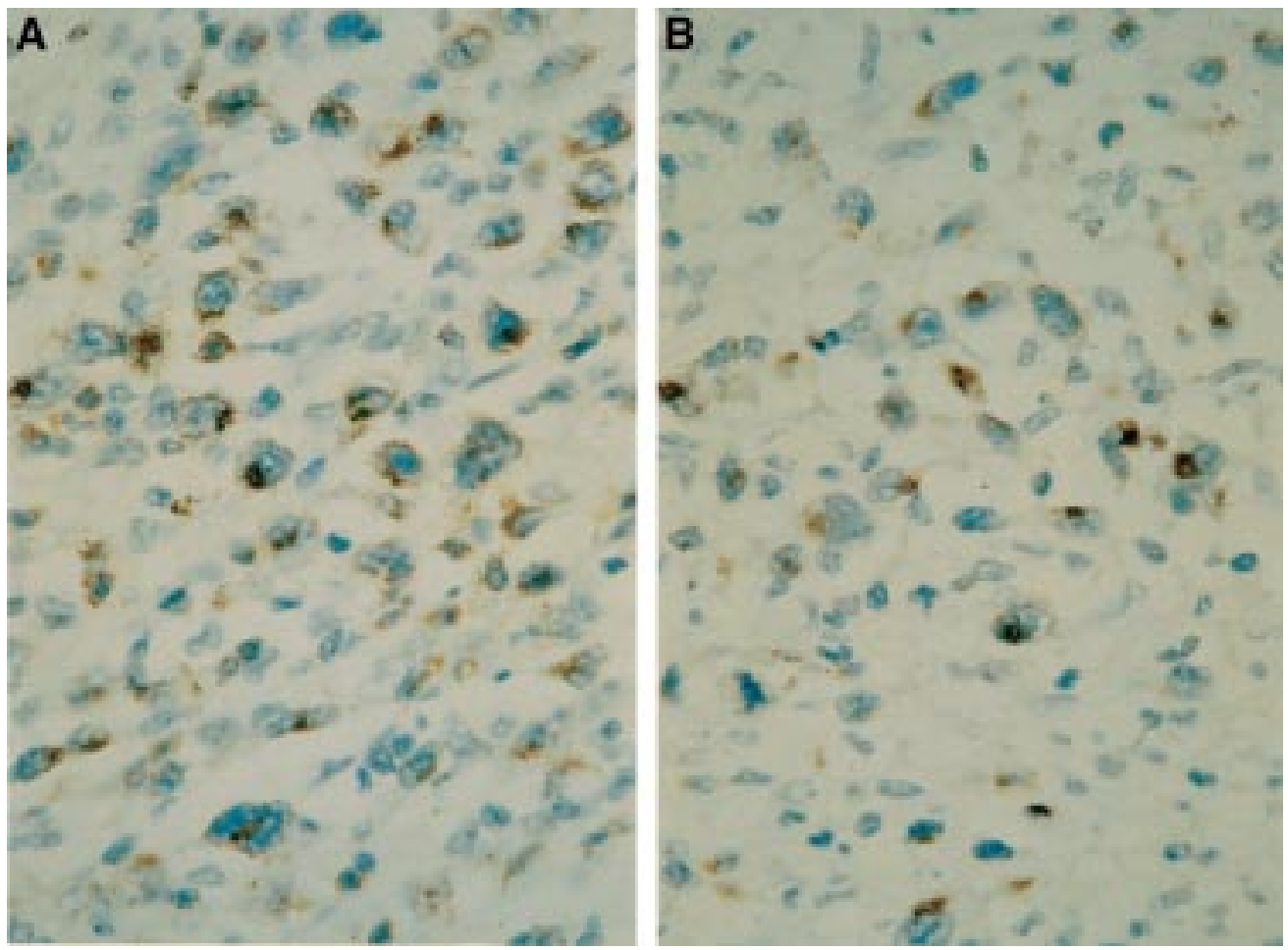

Figure 1 Anaplastic large cell lymphoma. (A) A strong granular TIA-1 specific signal (brown) is observed in the cytoplasm of the large majority of neoplastic cells. (B) A granular dot-like staining of granzyme B (brown) in the neoplastic cells of the same anaplastic large cell lymphoma. (Haematoxylin counterstaining.)

Patient characteristics are summarised in table 1 . The stage of the disease at first presentation was determined by standard staging procedures including full blood count, $x$ rays of the chest, computed tomography of the abdomen, bone marrow aspiration, and biopsy.

Except in three cases, all patients with nodal and gut associated tumours received polychemotherapy consisting of CHOP (cyclophosphamide, doxorubicin, vincristine, and prednisone) or CHOP-like regimens, some receiving involved field radiation alone $(\mathrm{n}=3)$ or in addition to chemotherapy $(n=9$, table 2$)$. One patient (No 39, table 2) died before treatment could be given, while another patient (No 40 , table 2) declined treatment on personal grounds. In 49 of the 59 cases, complete remission was achieved but 23 patients had a relapse.

IMMUNOHISTOCHEMISTRY

In all cases formalin fixed paraffin embedded tissue sections were used for immunohistochemical detection of granzyme B and TIA-1. The antibody raised against TIA-1 (Coulter Corporation) recognises a $15 \mathrm{kDa}$ protein in the cytoplasmic granules of potentially cytotoxic $T$ cells and belongs to the IgG1 subclass. ${ }^{1328}$ The production and characterisation of a granzyme $\mathrm{B}$ directed monoclonal antibody (GB7) has been described previously. ${ }^{15}$ Briefly, the IgG2a subclass monoclonal antibody was raised against recombinant human granzyme $\mathrm{B}$ and reacted with granzyme $B$ isolated from activated human cytotoxic lymphocytes and natural killer cells. Both
TIA-1 and GB7 can be applied on routine formalin fixed, paraffin embedded tissue specimens.

For granzyme B and TIA-1 detection, sections were boiled in citrate buffer $(0.01 \mathrm{M}$ pH 6.0) using a microwave oven $(2 \times 5$ minutes at $100^{\circ} \mathrm{C}$; maximum power $700 \mathrm{~W}$ ). They were then stained with monoclonal antibodies against granzyme B and TIA-1 (diluted 1:500 and 1:250, respectively) and incubated for one hour at room temperature, employing a three step method using a biotinylated rabbit antimouse monoclonal antibody and streptavidinbiotin-horseradish peroxidase (HRP) complex (Dako). Cases were further characterised using antibodies directed against CD3, CD4, CD8, and CD30 as well as B cell markers (CD20 and MB2 or CD79a).

ALK expression was detected using the monoclonal antibody ALK1 as described previously, ${ }^{29}$ with slight modifications. The ALK antibody was diluted 1:75 and slides were incubated overnight at $4^{\circ} \mathrm{C}$ and staining was enhanced using the CARD method. ${ }^{30}$

When double staining procedures were performed $(n=4)$, granzyme B and TIA-1 were applied simultaneously for 60 minutes at room temperature. Subsequently TIA-1 was detected using biotinylated goat anti-IgG1 and GB7 with goat anti-IgG2a conjugated with HRP and applied simultaneously for 30 minutes. Biotinylated goat anti-IgG1 (Southern Biotechnology Association) was detected using streptavidin Cy3 (Jackson Immunoresearch Laboratories) for 90 minutes, while goat anti-IgG2a HRP was detected by the deposition of fluorescein isothiocyanate 

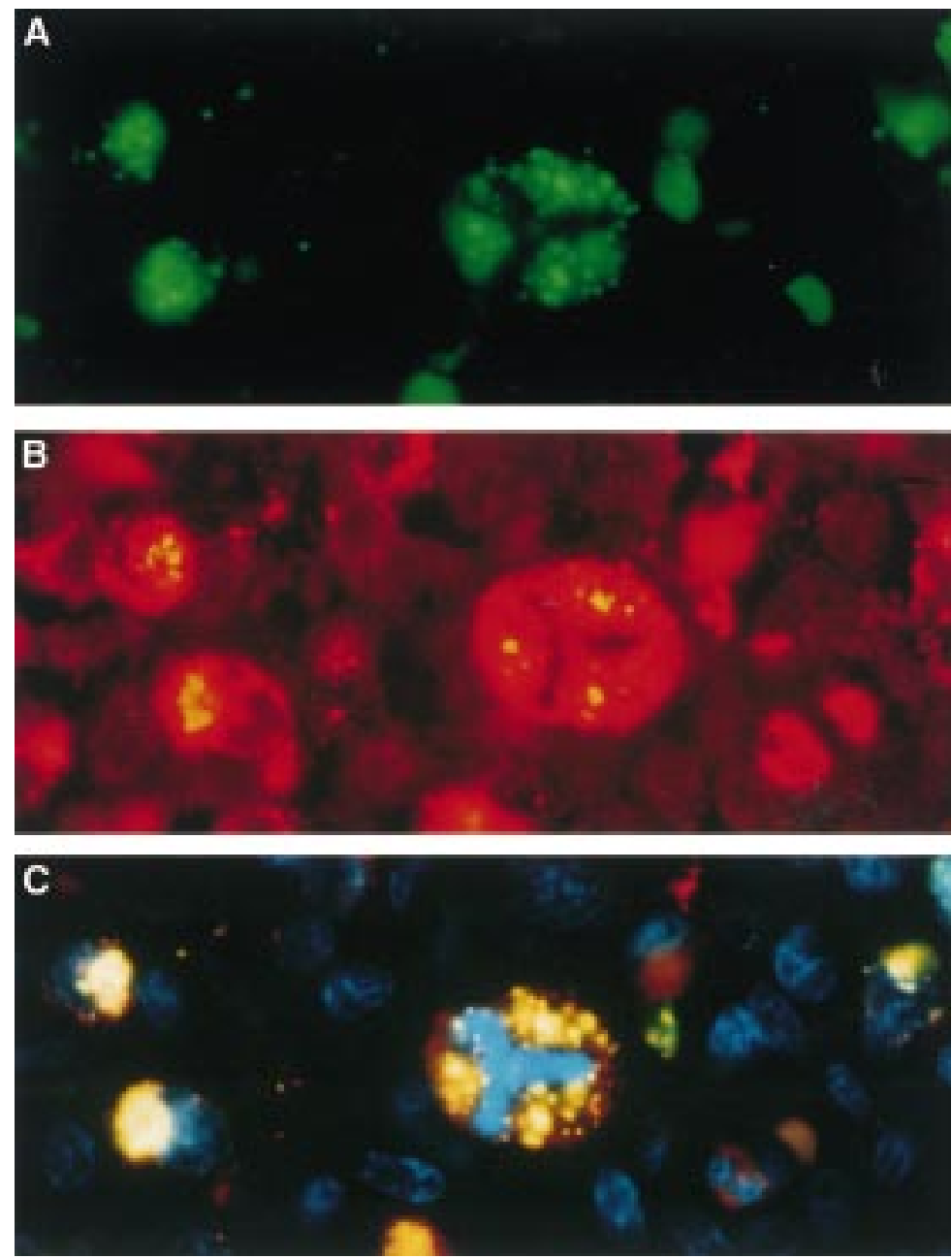

Figure 2 Double staining of granzyme $B$ and TIA-1 in a nodal anaplastic large cell lymphoma. (A) green staining (FITC conjugated tyramine) indicates granzyme $B$ expression in neoplastic cells. (B) TIA-1 (red), visualised by cy3 labelled streptavidin. Tumour cells showing a granular expression of TIA-1 in the cytoplasm. (C) Granzyme B/TIA-1 double staining as detected using a triple filter, simultaneously visualising coexpression of TIA-1 and granzyme B (yellow) and DAPI counterstained nuclei (blue).

(FITC) conjugated tyramine (15 minutes) as described previously. ${ }^{31}$ The sections were counterstained with DAPI and evaluated with a Leica DMRB fluorescence microscope.

Surrounding reactive lymphocytes were used as a positive internal control. Negative controls consisted of simultaneously processed slides with isotype specific antibodies instead of GB7 and TIA-1, respectively.

\section{RNA IN SITU HYBRIDISATION}

To demonstrate that granzyme $\mathrm{B}$ positive staining of tumour cells represented intracellular production rather than passive uptake from surrounding non-neoplastic reactive lymphocytes, RNA in situ hybridisation (RISH) was performed to detect granzyme $\mathrm{B}$ at the mRNA level $(n=4)$. The RISH procedure used has been described previously. ${ }^{32}$

INTERPRETATION OF IMMUNOHISTOCHEMICAL RESULTS

A case was considered to possess a cytotoxic phenotype when unequivocal staining of neoplastic cells (irrespective of the number of positive cells) for either TIA-1 or granzyme B was detected according to criteria described by Foss et al. ${ }^{10}$ The percentage of tumour cells staining positive for granzyme B and TIA-1 was quantified using a commercially available interactive video-overlay based measuring system (Q-Prodit, Leica), as described previously. ${ }^{21}$ The microscopic image was recorded by a charged coupled device camera and displayed on a monitor. A 40x objective was used, giving a final magnification of $1200 \times$, which appeared the most suitable for this purpose. One hundred fields of vision were systematically randomly selected using an automatic scanning stage controlled by Q-Prodit. In these fields at least 100 tumour cells, as determined by morphology, were sampled using a Weibel six point test grid (point distance $50 \mu \mathrm{m}$ ) and scored positive and negative for granzyme B or TIA-1. ${ }^{33}$

ANALYSIS OF CLINICAL DATA

For statistical analysis we used 59 biopsies from primary tumours from which the clinical data could be retrieved. For each patient the following characteristics were noted from the medical records: age, sex, clinical stage at first presentation, presence of B symptoms, response to treatment, occurrence of relapses, and cause of death. The median follow up time was 25 months (range 0 to 207 months). Survival time was measured from the time of initial diagnosis until death from the disease or until the date of last follow up. Patients who died of causes unrelated to the disease were censored at the time of death. Relapse-free survival time was measured from time of initial diagnosis until time of disease relapse. Patients who did not enter complete remission were assigned a relapse-free survival time of zero in the analysis.

STATISTICAL ANALYSIS

Survival curves were constructed with the Kaplan-Meier method. Differences between the curves were analysed using the log-rank test. Cox regression analysis ${ }^{34}$ (enter and remove limits 0.1 ) was used to investigate whether the percentage of granzyme B/TIA-1 positive tumour cells (when entered as a continuous variable) was related to prognosis. Comparisons of means were performed using the Student $t$ test or the Mann Whitney U test, where appropriate. Qualitative variables were analysed by Pearson $\chi^{2}$ test or by the Fisher exact test, where appropriate. All values were based on two tail statistical analysis. Probability (p) values below 0.05 were considered significant. All analyses were performed using the SPSS statistical software package.

\section{Results}

EXPRESSION OF CYTOTOXIC PROTEINS IN REACTIVE CELLS IN ALCL

In all cases tested, both granzyme B and TIA-1 positive non-neoplastic small reactive lymphocytes were found, thus serving as positive controls. In these cells a granular staining pattern was observed for either GB7 or TIA-1. The percentage of reactive lymphocytes 
Table 3 Patient and tumour characteristics of primary gut associated and cutaneous anaplastic large cell lymphomas $(A L C L)$

\begin{tabular}{|c|c|c|c|c|c|c|c|c|c|c|c|c|}
\hline Case & $G r B^{\star}$ & $T I A-1^{*}$ & $A L K$ & $C D 3$ & $C D 4$ & $C D 8$ & Stage & $R x$ & $C R$ & Rel & Survt & Status \\
\hline \multicolumn{13}{|c|}{ Gut associated $A L C L$ with a cytotoxic phenotype } \\
\hline 45 & 90 & 92 & - & + & - & - & III & PC & - & + & 1 & DOD \\
\hline 46 & 79 & 88 & - & + & + & - & III & PC & + & + & 13 & DOD \\
\hline \multicolumn{13}{|c|}{ Gut associated ALCL without a cytotoxic phenotype } \\
\hline 47 & 0 & 0 & - & + & + & - & II & $\mathrm{PC}+\mathrm{R}$ & + & - & 80 & AAW \\
\hline \multicolumn{13}{|c|}{ Cutaneous ALCL with a cytotoxic phenotype } \\
\hline 48 & 57 & 44 & - & + & + & - & I & $\mathrm{R}$ & + & - & 16 & DOC \\
\hline 49 & 20 & 60 & - & + & + & - & I & $\mathrm{R}$ & + & - & 13 & DOC \\
\hline 50 & 18 & 20 & - & + & + & - & I & None & + & - & 68 & AAW \\
\hline 51 & 14 & 23 & - & + & + & - & I & PC & + & - & 57 & AAW \\
\hline 52 & 11 & 15 & - & + & + & - & I & PC & + & - & 61 & AWD \\
\hline 53 & 9 & 15 & - & $+/-$ & + & - & I & PC & + & + & 85 & AWD \\
\hline 54 & 7 & 17 & - & + & + & - & I & $\mathrm{R}$ & + & - & 246 & AAW \\
\hline 55 & 5 & 11 & - & + & + & - & I & None & + & - & 32 & AAW \\
\hline \multicolumn{13}{|c|}{ Cutaneous ALCL without a cytotoxic phenotype } \\
\hline 56 & 0 & 0 & - & $+/-$ & + & - & I & PC & + & - & 123 & AAW \\
\hline 57 & 0 & 0 & - & + & - & - & I & PC & + & + & 47 & AAW \\
\hline 58 & 0 & 0 & - & + & + & - & $\mathrm{I}$ & None & + & + & 24 & AWD \\
\hline 59 & 0 & 0 & - & - & + & - & I & None & + & - & 36 & AAW \\
\hline
\end{tabular}

AAW, alive and well; ALK, anaplastic lymphoma kinase; AWD, alive with disease; CR, complete remission; DOC, died of other cause; DOD, died of disease; GrB, granzyme B; nd, not determined; PC, polychemotherapy; Rel, relapse; Rx, treatment; Surv, survival; TIA-1, T cell intracytoplasmic antigen.

$\star$ Percentage of positive neoplastic cells determined using the Q-Prodit system.

†Survival in months.

expressing granzyme $\mathrm{B}$ ranged from $1 \%$ to $61 \%$, whereas TIA-1 expression ranged from $9 \%$ to $75 \%$ of reactive lymphocytes.

EXPRESSION OF CYTOTOXIC PROTEINS IN

NEOPLASTIC CELLS OF ALCL

In 37 of the 59 cases studied (63\%), the neoplastic cells showed expression of TIA-1 and granzyme $\mathrm{B}$ in the tumour cells. In two additional cases only expression of TIA-1 was detected. For both TIA-1 and granzyme B, the characteristic granular or dot-like cytoplasmic staining in the neoplastic cells was observed (fig 1). The number of tumour cells staining positive for either granzyme B or TIA-1 ranged from a few positive tumour cells to over $90 \%$ of all tumour cells. All cases positive for granzyme $\mathrm{B}$ were also positive for TIA-1. In all but two cases, TIA-1 positive tumour cells outnumbered the granzyme B positive tumour cells (table 2). Coexpression of TIA-1 and granzyme $\mathrm{B}$ in the tumour cells was confirmed using double staining procedures, showing colocalisation of granzyme B and TIA-1 in the cytoplasmic granules in all four cases tested (fig 2).

CYTOTOXIC PHENOTYPE OF ALCL IN RELATION TO SITE OF ORIGIN

In nodal ALCL, both TIA-1 and granzyme B expression was found in tumour cells in 27 of 44 cases $(61 \%)$, with an additional two cases showing only TIA-1 expression. In cutaneous ALCL, expression of both TIA-1 and granzyme B in tumour cells was found in eight of 12 cases. In gut associated ALCL, two of three cases showed a cytotoxic phenotype (table 3). Thus the cytotoxic phenotype of ALCL was not associated with a certain site of origin.

Of the ALCL with a cytotoxic phenotype, the gut associated ALCL had the highest mean percentage of neoplastic cells expressing both TIA-1 and granzyme B, whereas in cutaneous lymphomas only a minority of the neoplastic cells showed expression of TIA-1 or granzyme $\mathrm{B}$ or both. The nodal ALCL cases showed a highly variable percentage of tumour cells with a cytotoxic phenotype, ranging from a few to more than $90 \%$ of tumour cells (table 2 ).

CYTOTOXIC PHENOTYPE OF ALCL IN RELATION TO ALK EXPRESSION

In nodal ALCL with a cytotoxic phenotype, 12 of 28 cases were ALK positive, compared with only one ALK positive case of 14 nodal ALCL without a cytotoxic phenotype $(p=0.02)$. No ALK expression was observed in gut associated and cutaneous cases (table 3 ).

CYTOTOXIC PHENOTYPE OF ALCL IN RELATION TO IMMUNOPHENOTYPE

It appeared that with two exceptions, all primary skin and gut associated ALCL were CD3+ and CD4+, irrespective of granzyme B/TIA-1 expression, whereas expression of $\mathrm{T}$ cell markers in nodal ALCL was found to be more heterogeneous. In nodal granzyme B/TIA-1 positive cases, five $\mathrm{CD} 3+/ \mathrm{CD} 4+$ / CD8 - cases were found, six cases positive for CD3 only, eight positive for CD4 only, one CD3-/CD4-/CD8+ case, and six CD3-/ CD4-/CD8- cases. These marker profiles did not differ significantly from nodal granzyme B/TIA-1 negative cases: three CD3+/CD4+/ CD8- cases, one case positive for CD3 only, five positive for CD4+ only, and three CD3-/ CD4-/CD8- cases (table 4).

RNA IN SITU HYBRIDISATION

Two cases (one nodal case and one gut associated ALCL) which were strongly positive for granzyme B by immunohistochemistry, and two cases (nodal ALCL) which were negative for granzyme B, were used for RISH. In these cases good RNA quality was shown by clear RISH signals for $\beta_{2}$ microglobulin. In both 
Table 4 Anaplastic lymphoma kinase (ALK) and T cell marker expression on neoplastic cells of primary nodal anaplastic large cell lymphomas (ALCL) with and without a cytotoxic phenotype

\begin{tabular}{llll}
\hline & \multicolumn{2}{l}{ Cytotoxic phenotype of ALCL } & \\
\cline { 2 - 3 } & Positive & Negative & p Value \\
\hline ALK & $(\mathrm{n}=28)$ & $(\mathrm{n}=14)$ & \\
Positive & 12 & 1 & \\
Negative & 16 & 13 & 0.02 \\
CD3 & $(\mathrm{n}=29)$ & $(\mathrm{n}=14)$ & \\
Positive & 11 & 6 & NS \\
Negative & 18 & 8 & \\
CD4 & $(\mathrm{n}=25)$ & $(\mathrm{n}=13)$ & \\
Positive & 13 & 8 & NS \\
Negative & 12 & 5 & \\
& & $(\mathrm{n}=12)$ & NS \\
CD8 & $(\mathrm{n}=28)$ & 0 & \\
Positive & 1 & 12 & \\
Negative & 27 & & \\
\hline
\end{tabular}

†A case was considered to possess a cytotoxic phenotype when unequivocal staining of neoplastic cells was observed irrespective of the number of cells staining positive. *As determined by Pearson $\chi^{2}$ test or Fisher exact test.

granzyme B positive cases, granzyme B could also be demonstrated at the mRNA level in the neoplastic cells in addition to some reactive infiltrating lymphocytes (fig 3). In cases with granzyme B negative tumour cells, no expression of granzyme B mRNA was detected in the neoplastic cells, whereas some infiltrating lymphocytes did express granzyme B specific mRNA. These data show that granzyme $B$ positive staining of tumour cells is not the result of passive uptake from surrounding nonneoplastic reactive lymphocytes but represents intracellular production.
PATIENT CHARACTERISTICS AND PROGNOSTIC VALUE OF NEOPLASTIC CELLS WITH A CYTOTOXIC PHENOTYPE

The clinical features of the 59 patients are summarised in table 1 . When all sites were included, no major differences in clinical presentation were observed between granzyme B+/TIA-1+ cases and granzyme B-/TIA-1cases. In both groups the majority of patients were between 25 and 50 years of age, with a mean of 46 years. Also no differences in stage at presentation were noticed.

Site of first presentation strongly influenced prognosis (table 5). This ranged from excellent in all cutaneous cases to moderate in nodal cases (five year survival 63\%). Two of three patients with a gut associated ALCL died as a result of the disease. As expected, ALK expression in nodal cases was found to be a highly favourable prognostic marker; none of 13 patients with ALK positive ALCL died, whereas 17 of 44 patients with ALK negative ALCL died as result of the disease $(p=0.008)$.

The presence of a cytotoxic phenotype did not appear to have any impact on prognosis for either overall survival or relapse-free survival time when determined by either Cox regression analysis or by log-rank test. Even when different arbitrary thresholds for a minimum percentage of tumour cells with a cytotoxic phenotype was applied (that is, $5 \%$, $10 \%, 15 \%, 20 \%, 30 \%$, or $50 \%$ positive tumour cells), no group with a relatively poor prognosis could be defined (fig 4). Also, when adjusted for either stage at presentation, site, or ALK status, no differences were found in either overall survival or relapse-free survival time.
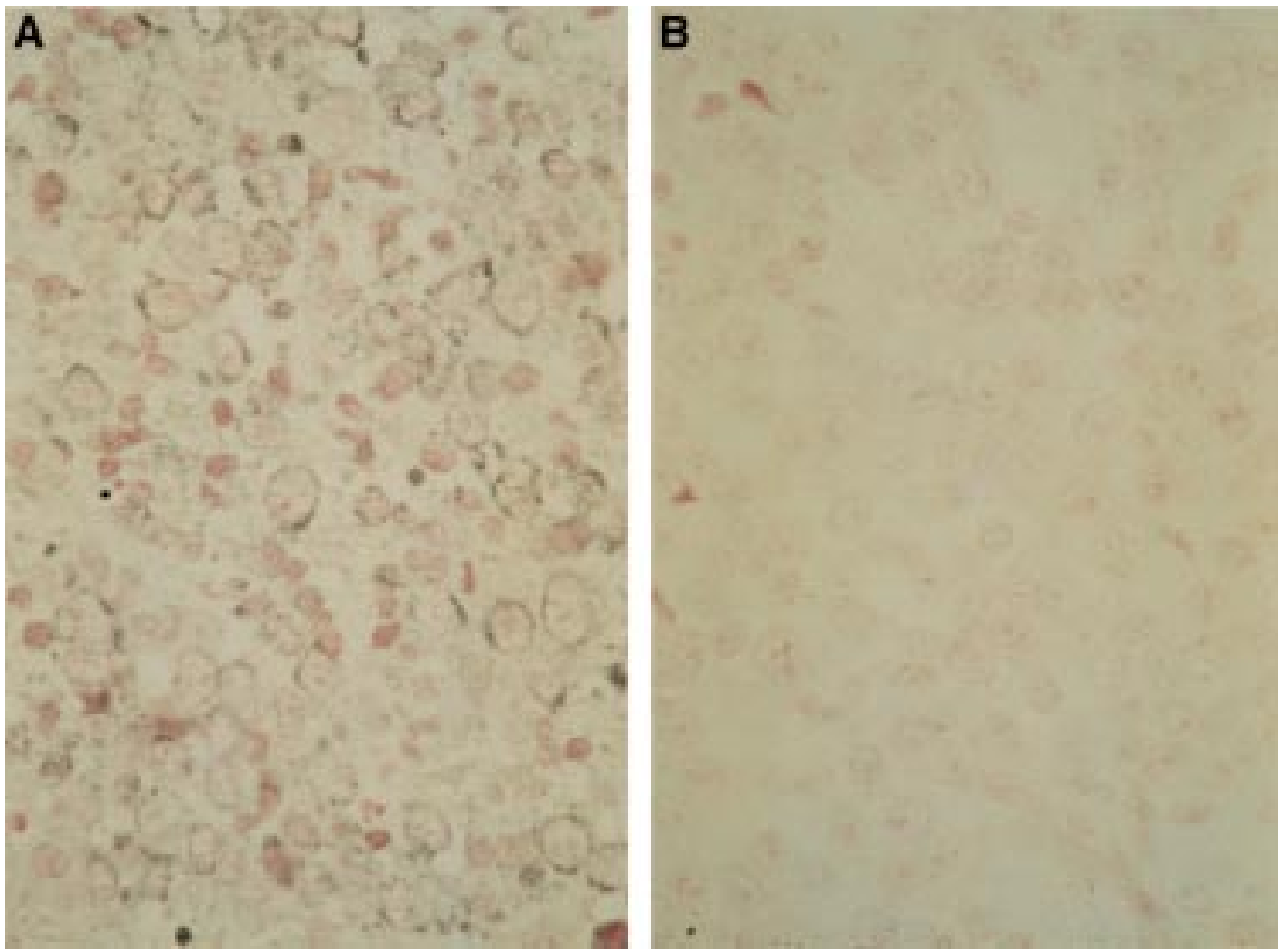

Figure 3 Granzyme B expression at the $m R N A$ level in neoplastic cells using RNA in situ hybridisation. (A) Using an anti-sense probe, strong black staining is observed in the cytoplasm of the neoplastic cells, indicating the presence of granzyme B specific mRNA. (B) Sense control (fast nuclear red counterstaining). 
Table 5 Data obtained by univariate survival analysis

\begin{tabular}{lllll}
\hline Characteristic & $n$ & $\begin{array}{l}\text { Deaths due to } \\
\text { ALCL }\end{array}$ & $\begin{array}{l}\text { Patients alive after 5 years } \\
(\%)^{*}\end{array}$ & $p$ Value \\
\hline $\begin{array}{l}\text { Cytotoxic phenotype } \\
\text { Positive }\end{array}$ & 39 & 11 & 67 & \\
$\quad$ Negative & 15 & 6 & 53 & NS \\
ALK & 13 & 0 & 100 & \\
$\quad$ Positive & 44 & 17 & 59 & 0.008 \\
$\quad$ Negative & 21 & 2 & 90 & \\
Stage & 14 & 2 & 83 & 0.0003 \\
I & 12 & 7 & 36 & \\
II & 12 & 6 & 50 & \\
III & 44 & 15 & 63 & 0.03 \\
IV & 3 & 2 & 33 & \\
Site & 12 & 0 & 100 & \\
Godal & & & \\
Cutroneous & & & & \\
\hline
\end{tabular}

†As estimated from Kaplan-Meier curves.

$\star$ Determined by log-rank test. with a relatively poor prognosis could be defined. Since (almost) equal percentages were observed for granzyme B/TIA-1 positive cases in nodal, cutaneous, and gut associated lymphomas, differences in clinical outcome between the different sites of origin cannot be ascribed to a cytotoxic phenotype of the neoplastic cells. In addition, the fact that nearly all ALK positive cases (with an excellent prognosis) also show a cytotoxic phenotype further emphasises that a cytotoxic phenotype is not necessarily related to a poor clinical outcome.

ALCL with a cytotoxic phenotype were hardly ever CD8 positive. In only one of 38 tested lymphomas possessing a cytotoxic phenotype did the tumour cells express CD8 (a nodal case), whereas 22 of 35 tested granzyme B/TIA-1 positive cases were CD4 positive. However, differences were noted for the different sites: all primary granzyme B/TIA-1 positive cutaneous cases and one of two gut associated cases were CD3+/CD4+/CD8-, whereas granzyme B/TIA-1 positive nodal ALCL cases showed considerable heterogeneity in T cell marker phenotype: CD4+/CD8-, CD4-/CD8+, or CD4- and CD8-. The fact that many granzyme B/TIA-1 positive cases are $\mathrm{CD} 4$ rather than $\mathrm{CD} 8$ positive is remarkable since in healthy individuals the majority of granzyme B/TIA-1 positive cytotoxic $\mathrm{T}$ lymphocytes are CD8 positive. Investigation of tumours without $\mathrm{T}$ cell marker expression revealed that these cases were also negative for natural killer cell markers CD56 and CD57 (data not shown). The biological relevance of CD4 positive cytotoxic $\mathrm{T}$ lymphocytes in normal immune surveillance is still unclear, but seems limited since these cells are sporadically detected in vivo and can be found only after prolonged cultivation in vitro in the presence of cytokines and antigen. ${ }^{36-40}$ Recent data indicate that $\mathrm{CD} 4$ positive cytotoxic $\mathrm{T}$ cells can acquire an activated cytotoxic phenotype in the presence of $\gamma$ interferon at high concentrations. ${ }^{41}$ However, this was only observed in the absence of activated CD8 positive cytotoxic T cells.

Since cutaneous ALCL are consistently CD3/CD 4 positive and CD8 negative, these lymphomas may be the neoplastic counterparts of a unique site specific subset of cytotoxic CD4 positive $\mathrm{T}$ cells, ${ }^{12}$ whereas nodal cases may originate from different subsets of potentially cytotoxic T cells. Another possibility is that these cases arise from CD 4 positive, CD8 negative $\mathrm{T}$ cells that acquire a cytotoxic phenotype on long term antigenic stimulation or on activation by the presence of high levels of certain cytokines. ${ }^{42}$ One indication that cytokine levels may be involved in the cytotoxic phenotype of tumour cells is the fact that TIA-1 positive tumour cells usually outnumbered the number of granzyme B positive tumour cells. Cytotoxic $\mathrm{T}$ cells express granzyme B only after activation with interleukin (IL)-2, IL-9, or IL-12, ${ }^{43-45}$ whereas TIA-1 is expressed in all potentially cytotoxic cells. Thus differences in local cytokine concentrations might account for the differences in activation stage and thus for the different expression patterns for TIA-1 and granzyme $\mathrm{B}$. 
In conclusion, in the majority of cases, ALCL are a proliferation of CD4 positive $\mathrm{T}$ lymphocytes with an activated cytotoxic phenotype. The presence of such a cytotoxic phenotype in primary biopsies of patients with ALCL is not related to site of origin, ALK expression, or clinical outcome of the disease.

KP was supported by the Leukaemia Research Fund, grant No 9646

1 Agnarsson BA, Kadin ME. Ki-1 positive large cell lymphoma: a morphologic and immunologic study of 19 cases. Am $₹$ Surg Pathol 1988;12:264-74.

2 Harris NL, Jaffe ES, Stein H, et al. A revised EuropeanAmerican classification of lymphoid neoplasms: a proposal American classification of lymphoid neoplasms: a proposal
from the International Lymphoma Study Group. Blood from the Internation

3 Shiota M, Nakamura S, Ichinohasama R, et al. Anaplastic large cell lymphomas expressing the novel chimeric protein p80NPM/ALK: a distinct clinicopathological entity. Blood 1995;86:1954-60.

4 Mason DY, Bastard C, Rimokh R. CD30 positive large cell lymphomas ( $\mathrm{Ki}-1$ lymphoma) are associated with a chromosomal translocation involving 5q35. Br f Haematol 1990;74:161-8.

5 Morris SW, Kirstein MN, Valentine MB, et al. Fusion of a kinase gene, ALK, to a nucleolar gene, NPM, in non-Hodgkin's lymphoma. Science 1994;263:1281-4.

6 Le Beau MM, Bitter MA, Larson RA, et al. t (2;5) (p23;q35): a recurring chromosomal abnormality in $\mathrm{Ki}-1$ positive anaplastic large cell lymphoma. Leukemia 1989;12:866-70.

7 Bitter MA, Franklin WA, Larson RA, et al. Morphology in Ki-1 (CD30)-positive non-Hodgkin's lymphoma is correlated with clinical features and the presence of a unique lated with clinical features and the presence of a unique
chromosomal abnormality, $\mathrm{t}(2 ; 5)(\mathrm{p} 23 ; \mathrm{q} 35)$. Am $\mathcal{F}$ Surg Pathol 1990;14:305-16.

8 Sandlund JT, Pui CH, Roberts M, et al. Clinicopathological features and treatment outcome of children with large cell lymphoma and the $\mathrm{t}(2 ; 5)(\mathrm{p} 23 ; \mathrm{q} 35)$. Blood 1994;84:246771.

9 Bruin de PC, Kummer JA, Valk van der P, et al. Granzyme B expressing peripheral T-cell lymphomas: neoplastic equivalents of activated cytotoxic T-cells with preference for mucosa associated lymphoid tissue (MALT) localization. Blood 1994;84:3785-91.

10 Foss HD, Anagnostopoulos I, Araujo I, et al. Anaplastic large cell lymphomas of T-cell and null cell phenotype express cytotoxic molecules. Blood 1996;88:4005-11.

11 Krenacs L, Wellmann A, Sorbara L, et al. Cytotoxic cell antigen expression in anaplastic large cell lymphomas of $\mathrm{T}$ and null cell type and Hodgkins disease: evidence for distinct cellular origin. Blood 1997;89:980-9.

12 Kummer JA, Vermeer MH, Dukers D, et al. Most primary cutaneous CD30 positive lymphoproliferative disorders have a CD4 positive cytotoxic T-cell phenotype. F Invest have a CD4 positive cytotoxic
Dermatol 1997;109:636-40.

13 Anderson P, Nagler-Anderson C, O'Brien C, et al. A monoclonal antibody reactive with a $15 \mathrm{kDa}$ cytoplasmic granule-associated protein defines a subpopulation of CD8+ T-lymphocytes. F Immunol 1990;144:574-82.

14 Kägi D, Ledermann B, Bürki K, et al. Cytotoxicity mediated by T-cells and natural killer cells is greatly impaired in perforin-deficient mice. Nature 1994;369:31-7.

15 Kummer JA, Kamp AM, Katwijk van M, et al. Production and characterization of monoclonal and polyclonal antibodies raised against recombinant human granzymes A and $\mathrm{B}$ and crossreacting with the natural proteins. $\mathcal{F}$ Immunol Methods 1993;163:77-83.

16 Heusel JW, Hanson RD, Silverman GA, et al. Structure and expression of a cluster of human hematopoietic serine protease genes found on chromosome 14q11.2. F Biol Chem 1991;266:6152-8.

17 Hanson RD, Sclar GM, Kanagawa O, et al. The 5' flanking region of the human CGL-1/granzyme B gene targets expression of a reporter gene to activated T-lymp.
transgenic mice. $\mathcal{F}$ Biol Chem 1991;266:24433-8.

18 Anderson P. TIA-1: structural and functional studies on a new class of cytolytic effector molecule. Curr Top Microbiol Immunol 1995;198:131-43.

19 Muller C, Tschopp J. Resistance of cytotoxic T cells to perforin-mediated lysis. Evidence for a lymphocyte membrane protein interacting with perforin. F Immunol 1994 153:2470-8.

20 Sun JR, Bird CH, Sutton V, et al. A cytosolic granzyme B inhibitor related to the viral apoptotic regulator cytokine response modifier A is present in cytotoxic lymphocytes. $\mathcal{f}$ Biol Chem 1996;271:27802-9.
21 Oudejans JJ, Jiwa NM, Kummer JA, et al. Activated cytotoxic T-cells as prognostic marker in Hodgkin's cytotoxic T-cells as prognostic
disease. Blood 1997;89:1376-82.

22 Muzio M, Chinnaiyan AM, Kischkel FC, et al. FLICE, a novel FADD-homologous ICE/CED-3-like protease is recruited to the CD95 (Fas/APO-1) and TNF receptorinduced cell death. Cell 1996;85:817-27.

23 Martin SJ, Amarante-Mendez GP, Shi L, et al. The cytotoxic cell protease granzyme B initiates apoptosis in a cell free system by proteolytic processing and activation of the ICE/CED-3 family protease, CCP32, via a novel two-step mechanism. EMBO $\mathcal{A} 1996 ; 15: 2407-16$.

24 Quan LT, Tewari M, O'Rourke K, et al. Proteolytic activation of the cell death protease Yama/CCP32 by granzyme B. Proc Natl Acad Sci USA 1996;93:1972-6.

25 Beljaards RC, Meijer CJ, Scheffer E, et al. Prognostic significance of CD30 (Ki-1/Ber-H2) expression in primary cutaneous large-cell lymphomas of T-cell origin. A clinicopathologic and immunohistochemical study in 20 patients. Am f Pathol 1989;135:1169-78

26 Beljaards RC, Meijer CJ, Van der Putte SC, et al. Primary cutaneous T-cell lymphoma: clinicopathological features and prognostic parameters of 35 cases other than mycosis
fungoides and CD 30 -positive large cell lymphoma. F Pathol fungoides and CD

27 Stansfeld AG, Diebold J, Noel H, et al. Updated Kiel classification for lymphomas. Lancet 1988 ;i:292-3.

28 Kawakami A, Tian Q, Streuli M, et al. Intron-exon organization and chromosomal localization of the human TIA-1 gene. F Immunol 1994;152:4937-45.

29 Pulford K, Lamant L, Morris SW, et al. Detection of anaplastic lymphoma kinase (ALK) and nucleolar protein nucleophosmin (NPM)-ALK proteins in normal and neoplastic cells with the monoclonal antibody ALK1. Blood 1997;89:1394-404.

30 Bobrow MN, Shaughnessy KJ, Litt GJ. Catalysed reporter deposition: a novel method of signal amplification. II. Application to membrane immunoassays. F Immunol Methods 1989;125:279-88.

31 Raap AK, Corput van der MPC, Vervenne RAW, et al. Ultra sensitive FISH using peroxidase-mediated deposition of biotin or fluorochrome tyramides. Hum Mol Genet 1995;4: 529-34.

32 Jiwa NM, Kanavaros P, Valk van der P, et al. Expression of c-myc and bcl-2 oncogene products in Reed-Sternberg cells independent of presence for EBV. F Clin Pathol 1993; 46:211-17.

33 Fleege JC, van Diest PJ, Baak JPA. Computer assisted efficiency testing of different sampling methods for selective nuclear graphic tablet morphometry. Lab Invest 1990;63:270-5

34 Cox DR. Regression models and life tables. I R Stat Soc 972;34:187-9.

35 Boulland ML, Kanavaros P, Wechsler J, et al. Cytotoxic protein expression in natural killer cell lymphomas and in $\alpha \beta$ and $\gamma \delta$ peripheral T-cell lymphomas. F Pathol 1997;183: 432-9.

36 Braakman E, Rotteveel FTM, Bleek van G, et al. Are MHC class II restricted cytotoxic T-lymphocytes important? Immunol Today 1987;8:265-9.

37 Fleischer B. Acquisition of specific cytotoxic activity in human T4+ T-lymphocytes in culture. Nature 1984;308: 365-7.

38 Susskind $\mathrm{B}$, Shornick MD, Ianotti MR, et al. Cytolytic effector mechanisms of human CD4+ cytotoxic T-lymphocytes. Cell 1996;45:64-75.

39 Matutes E, Coelho E, Aguada MJ, et al. Expression of TIA-1 and TIA-2 in T cell malignancies and T cell lymphocytosis. I Clin Pathol 1996;49:154-8.

40 Yasukawa M, Utsunomiya Y, Inoue Y, et al. Monoclonal proliferation of CD4+ large granular lymphocytes with cytolytic activity. Br f Haematol 1995;91:419-20.

41 Williams NS, Engelhard VH. Perforin-dependent cytotoxic activity and lymphokine secretion by $\mathrm{CD} 4+\mathrm{T}$ cells are regulated by CD8+ T cells. F Immunol 1997;159:2091-9.

42 Oberhuber G, Vogelsang H, Stolte M, et al. Am J Pathol 1998;148:1351-7.

43 Loeffler CM, Smith MJ, Longo DL, et al. Immunoregulation in cancer bearing hosts: downregulation of gene expression and cytotoxic function in CD8+ T-cells. F Immunol 1992;149:949-56.

44 Loeahed J, Kermouni A, van Snick J, et al. IL-9 induces expression of granzymes and high-affinity IgE receptor in murine T helper clones. F Immunol 1995;154:5061-70.

45 Chouaib S, Chehimi J, Bani L, et al. Interleukin 12 induces the differentiation of major histocompatibility complex class I primed cytotoxic T-lymphocytes precursors into allospecific cytotoxic effectors. Proc Natl Acad Sci USA 1995;91:12659-63. 